\title{
Worldviews: Art, Cartography, and the Power of Places Beyond
}

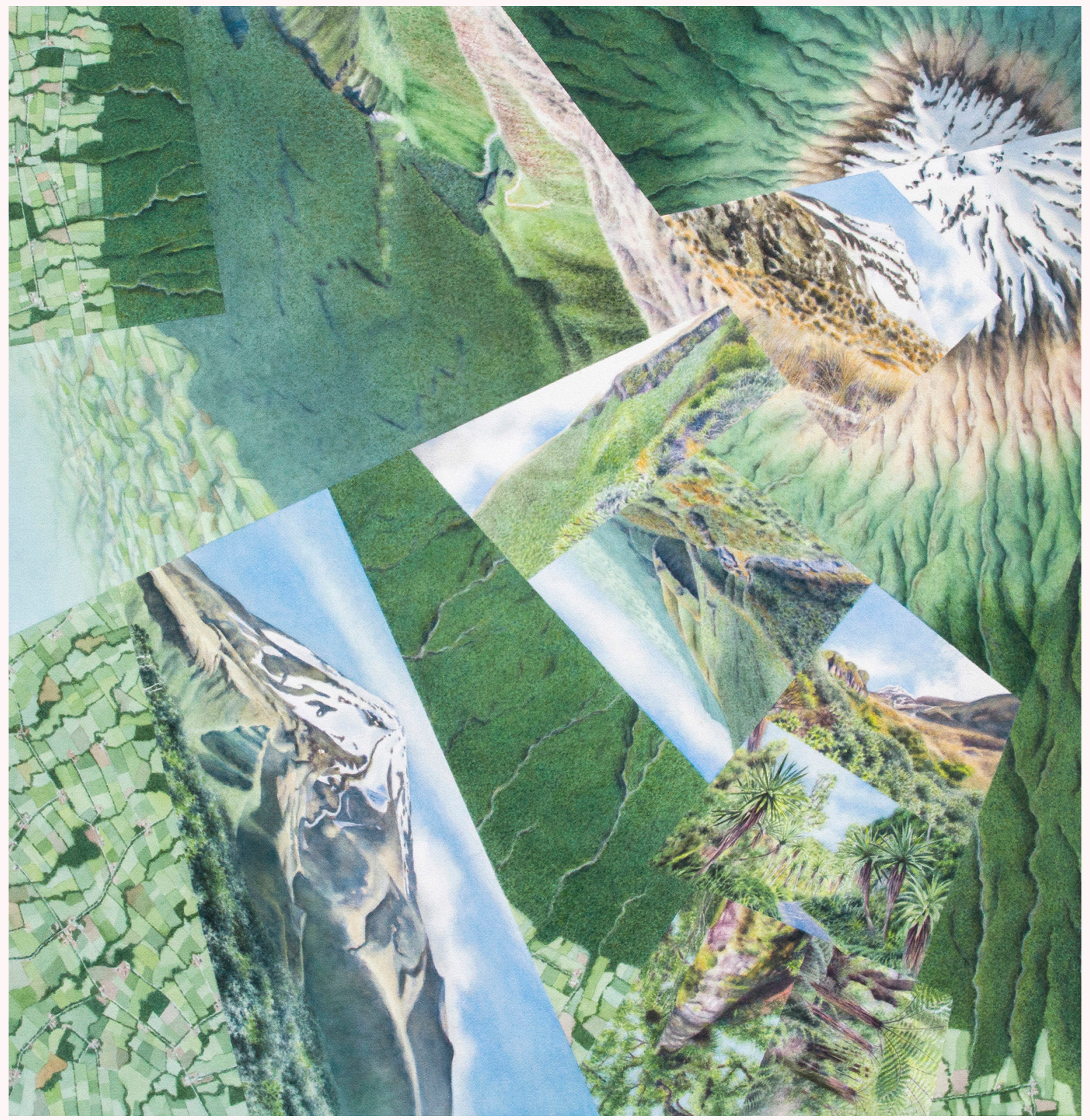

Cone (2020), inspired by Mt. Taranaki in New Zealand. Watercolor on paper, 36"×36". 
I AM ATTRACTED to maps for the same reason that I would guess many people are-they compress and organize large, complex pieces of the world onto tiny surfaces, giving me the empowering feeling of fully "knowing" those places. Some locations, though, feel compressed even before they are put on paper, making that sense of empowerment much stronger because I can explore them in the real world.

I remember my interest in these kinds of places beginning in childhood, and then strengthening when I started visiting them as a teenager. Most formative were the Hawaiian and Galápagos Islands, and Tanzania's Ngorongoro Crater, all with dramatic ecological gradients from wet to dry. Such contrasts are usually associated with entire continents, yet on these tropical islands and mountains it is possible to experience them within the span of only a few minutes. This idea of miniaturization also explains my long fascination with small volcanic cones and craters. I have a mental image of volcanoes as unapproachable and overpowering in scale and force, but when a volcano is "humanized"-accessible, easy to climb up and into, and isolated within some other contrasting landscape like a city-I experience a similar sense of empowerment.

This early obsession with environmental contrasts and microcosms probably developed

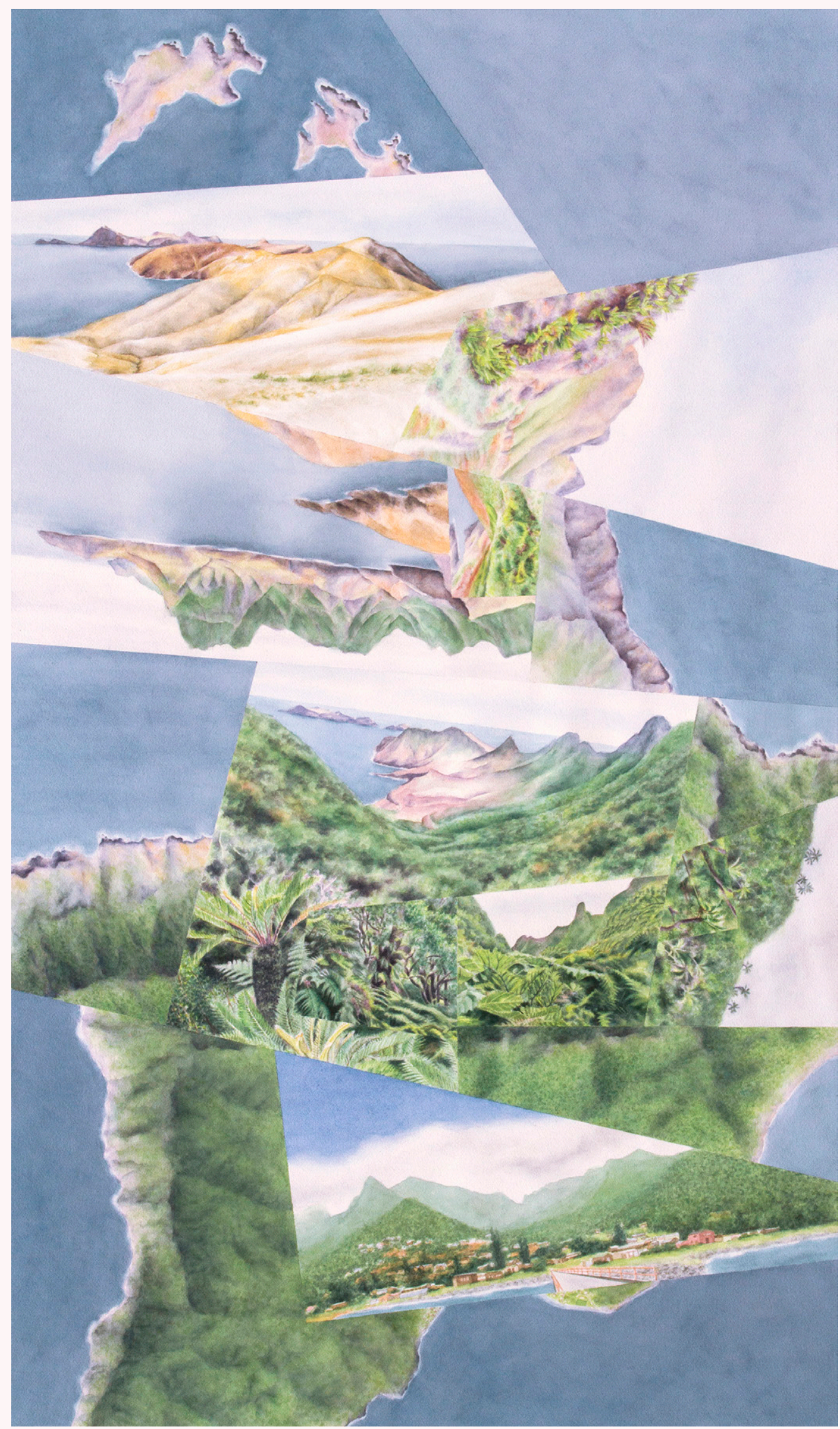

Mirador (2020), inspired by Robinson Crusoe Island in the Juan Fernández archipelago, Chile. Watercolor on paper, 48"×28". 


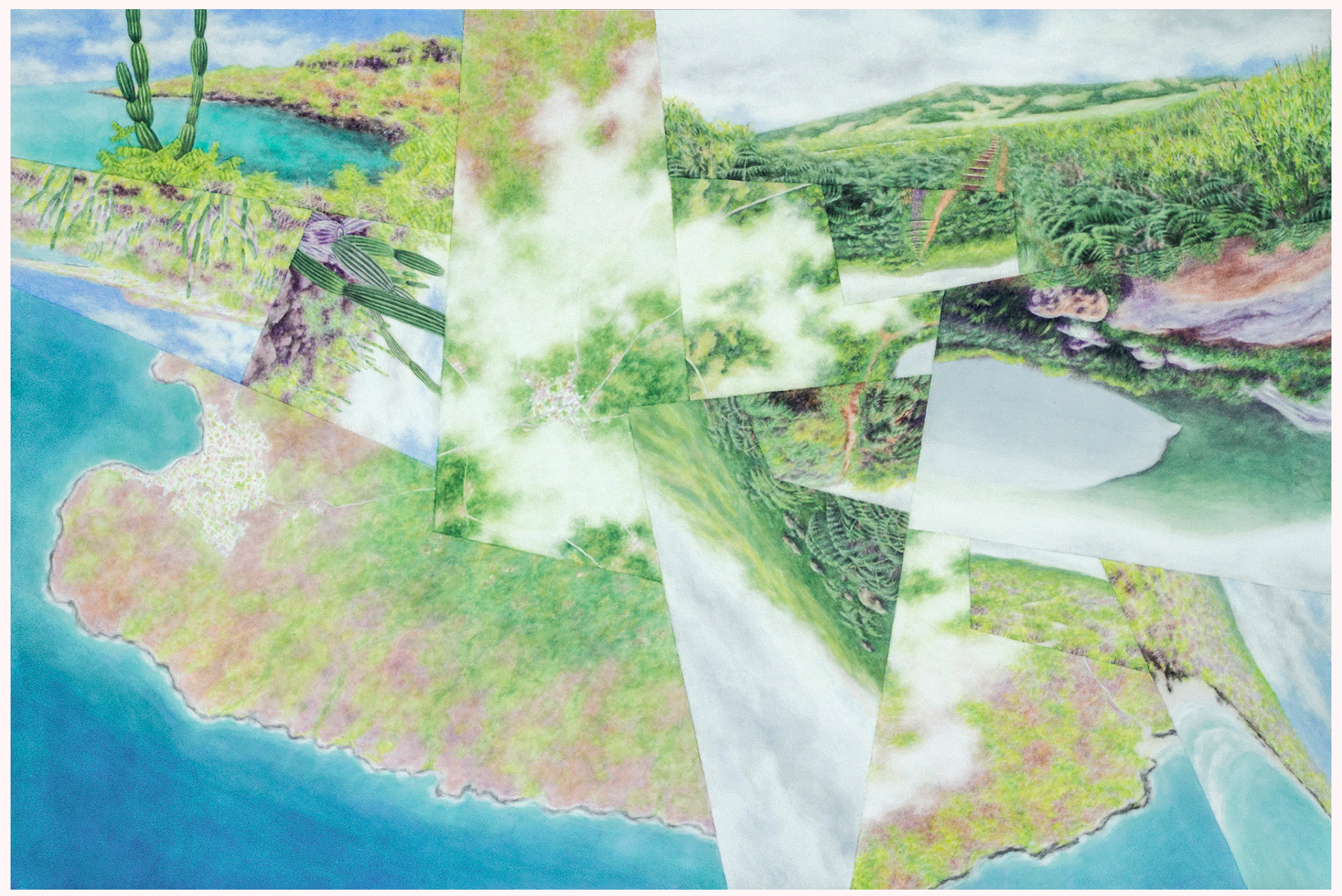

Highlands (2020), inspired by San Cristóbal Island in the Galápagos. Watercolor on aquabord, 24"×36".

in part due to boredom with what I perceived to be the monotonous landscape of my native Ohio. It also conforms to an ongoing tendency toward ambivalence and the-grass-is-always-greener thinking in many areas of my life-I feel a lack of control when forced to satisfy myself with one thing at the expense of all the different possibilities I can imagine. That same feeling arises when I visit a landscape too big and undefined for me to fully comprehend and see beyond.

I think of these environmental microcosms as "lived maps." They include islands and landscape patchworks of many kinds, whether the edges separate desert and oasis, mountain and plain, land and water, or nature and city. Though they might not represent the downsizing of geological or climatic phenomena as radically as the volcano and rainfall gradient examples, I still experience them as normally massive and overwhelming entities made small, distinct, and comprehensible.

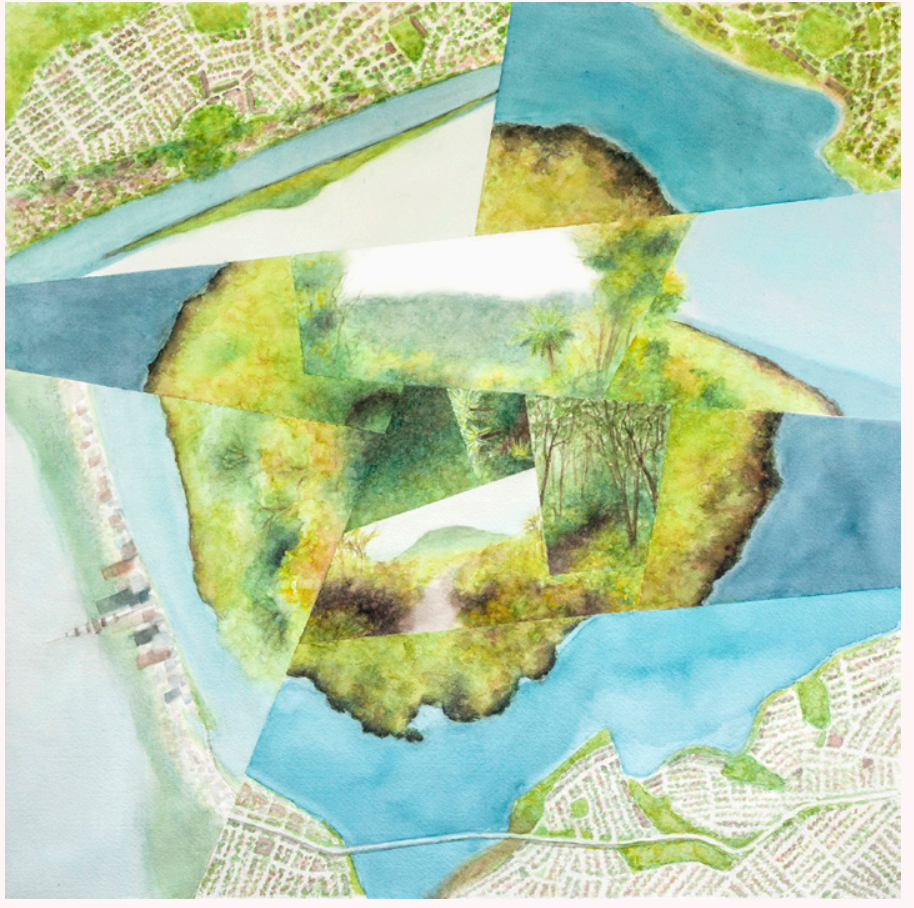

Harbour Island (2018), inspired by Rangitoto, a volcano just offshore from Auckland, New Zealand. Watercolor on paper, $18 " \times 18 "$. 


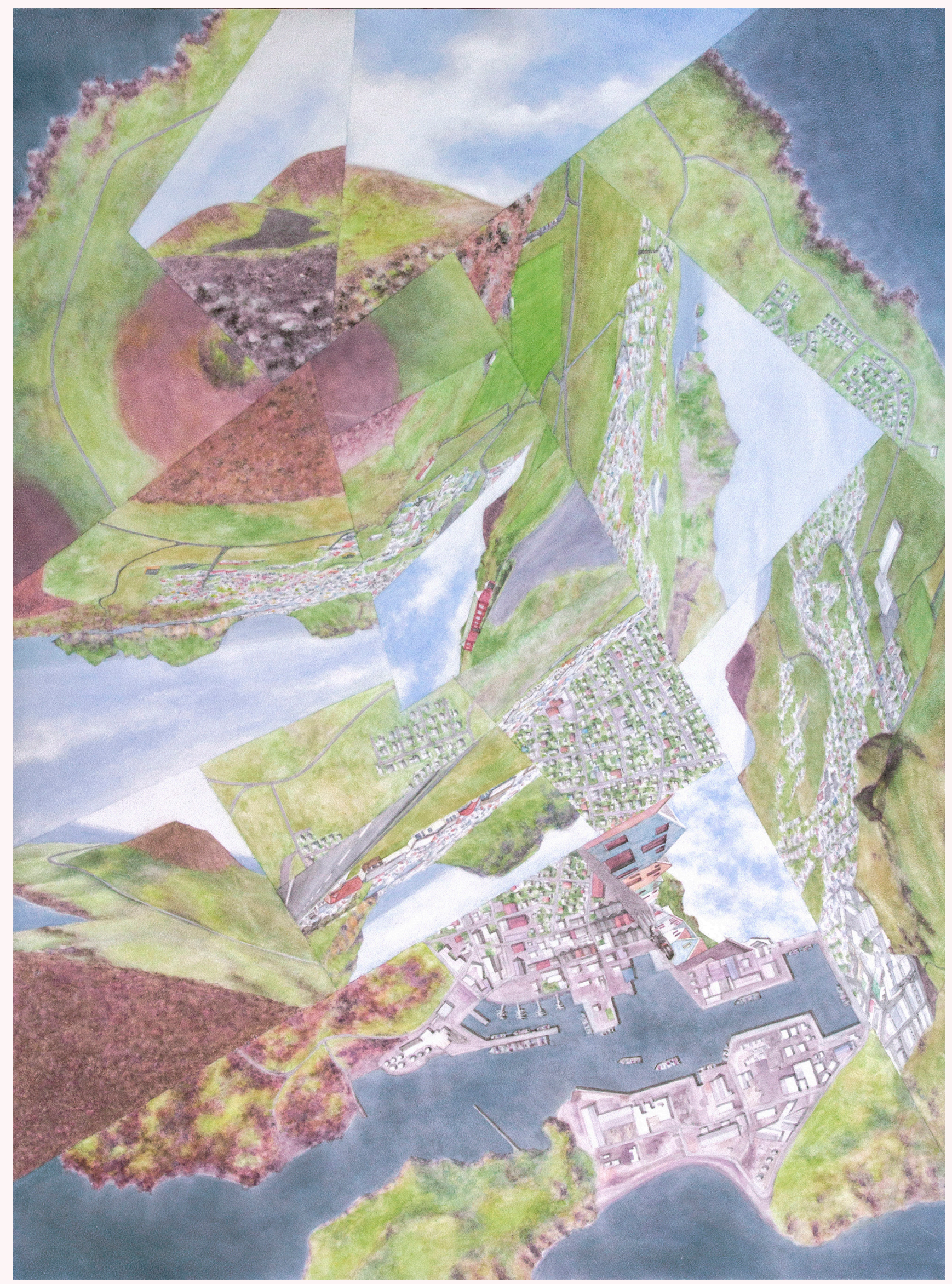

Sacred Hill (2020), inspired by the volcanic cone Helgafell on the island of Heimaey, Iceland. Watercolor on aquabord, $30 " \times 22 "$. 


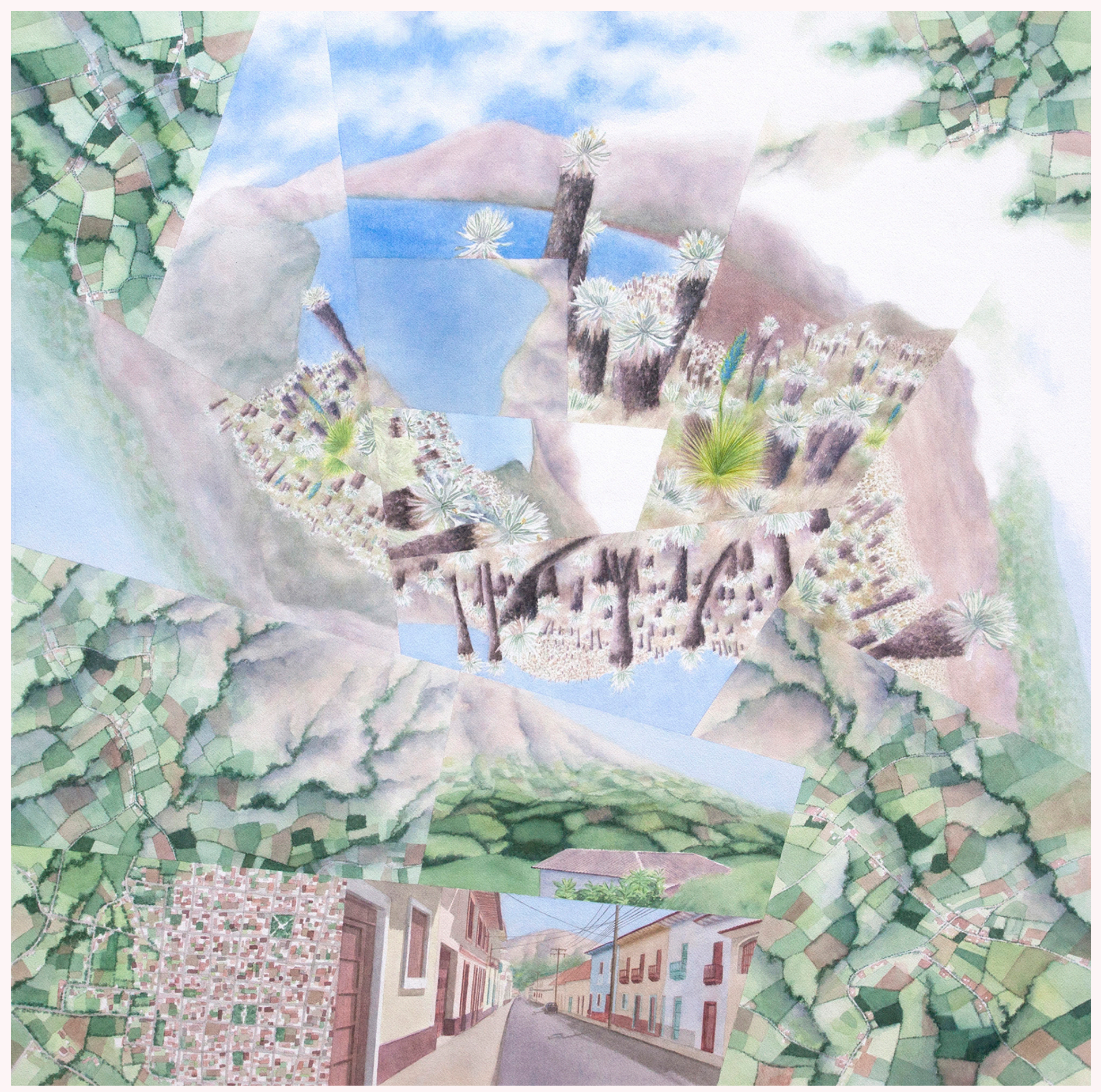

Lagoon (2019), inspired by the ecological preserve and village of El Ángel, Ecuador. Watercolor on paper, 36"×36".

After exploring these lived maps I still have the urge to compress and structure them further. This led me to the field of landscape architecture and then, after realizing that the profession would give me only limited opportunities to follow this particular passion out in the real world, to instead re-imagine them in two dimensions. That was fifteen years ago, and those works have since evolved from photomontages to oils to watercolors, each composition now a mix of landscape and aerial perspectives based mostly on my own photography and on satellite imagery. I have recently begun to call them worldvierws, alluding to the fact that each work depicts a complete, multi-dimensional 


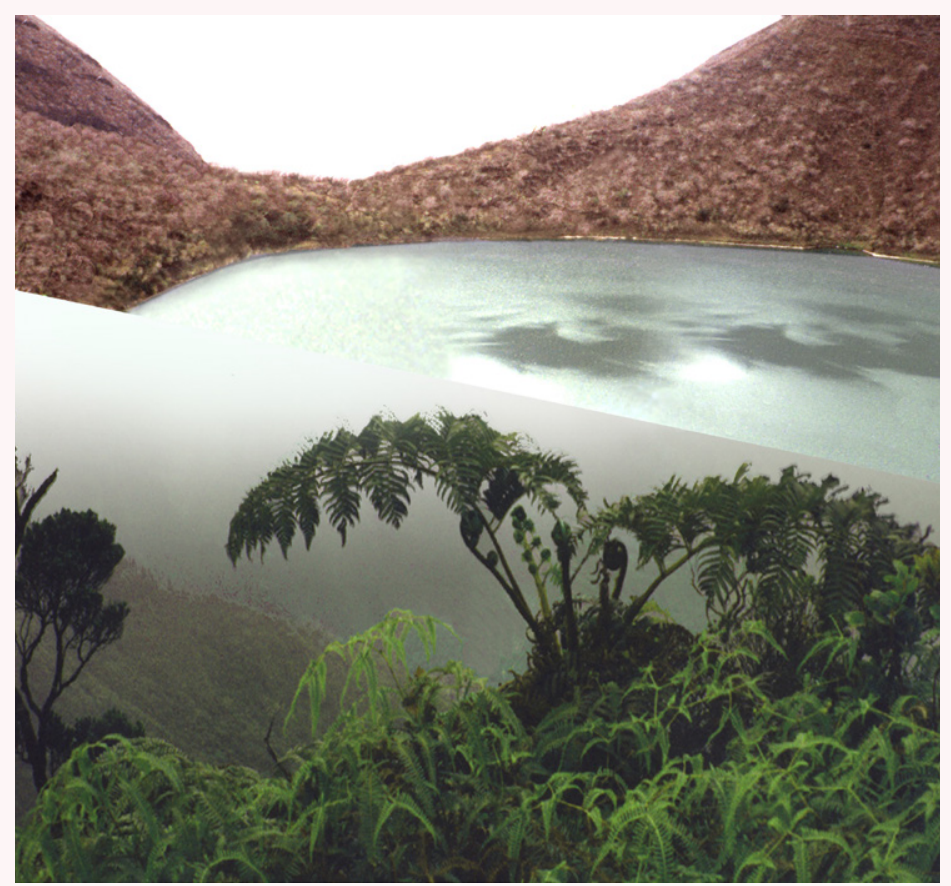

Two-sided Lake (2010), an imaginary juxtaposition of the highlands of Kavai with a crater lake on Isabela Island in the Galápagos. Photomontage, giclée print $36 " \times 40 "$.

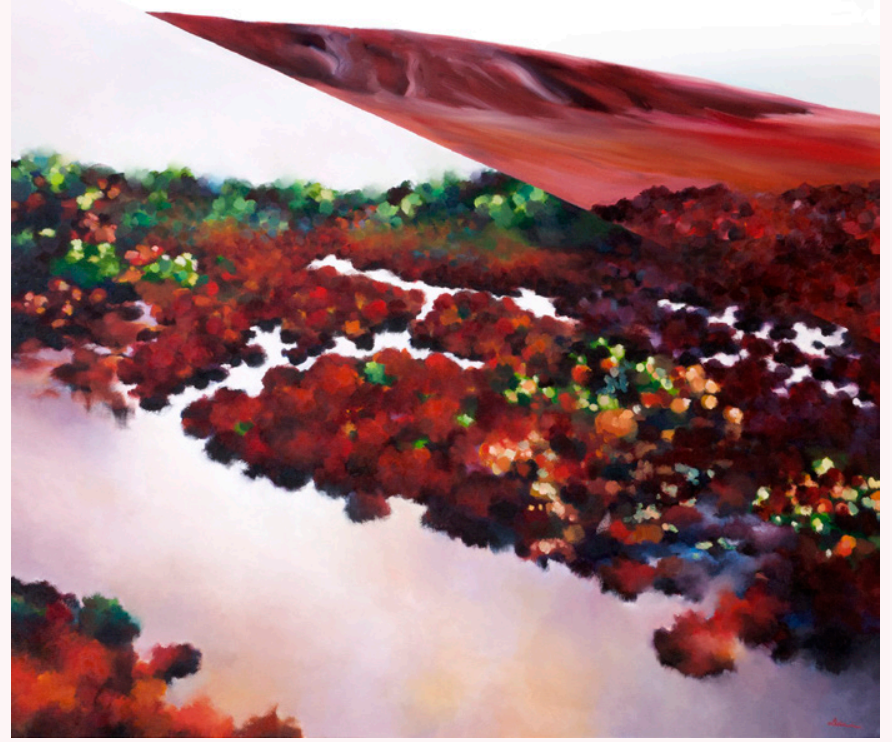

High Desert (2012), an imaginary juxtaposition of Death Valley in California with the Alakai Swamp on Kauai. Oil on canvas, $48 " \times 48 "$

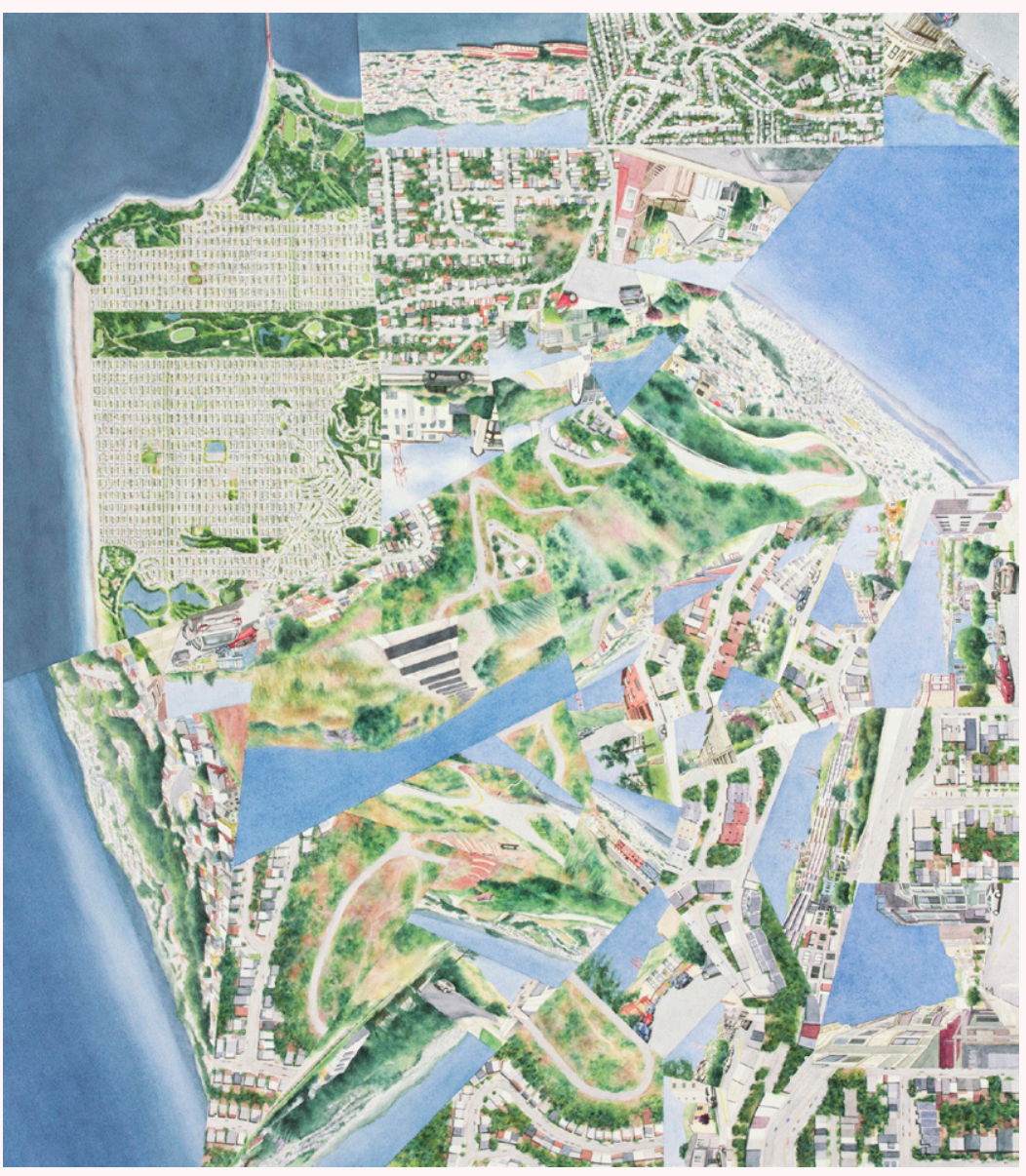

Peaks (2020), inspired by Twin Peaks in San Francisco. Watercolor on paper, $42 " \times 37 "$. "world" — the full experience of a place-rather than an individual snapshot or a purely bird's-eye perspective. They are different from most maps in having this experiential quality, preserving some of that "lived" aspect. Yet I no longer think of them as paintings per se: the term worldviews also references the particular way that I view the world, namely in spatial rather than scenic terms. An individual landscape means little to me unless I can journey to where it ends and beyond, just as knowledge of darkness gives meaning to light. Depicting a landscape in isolation holds no interest for me-even the process of painting the individual perspectives making up each worldview is much less engaging than designing the relationships between them-essentially, drawing the map.

Some of the worldviews depict roughly linear "journeys" through a sequence of landscapes, while others convey less-directed "wanderings." So far they draw on my memories and photographs from about fifteen countries on six continents, with a current focus on my recent travels in Oceania and South America. The representations 


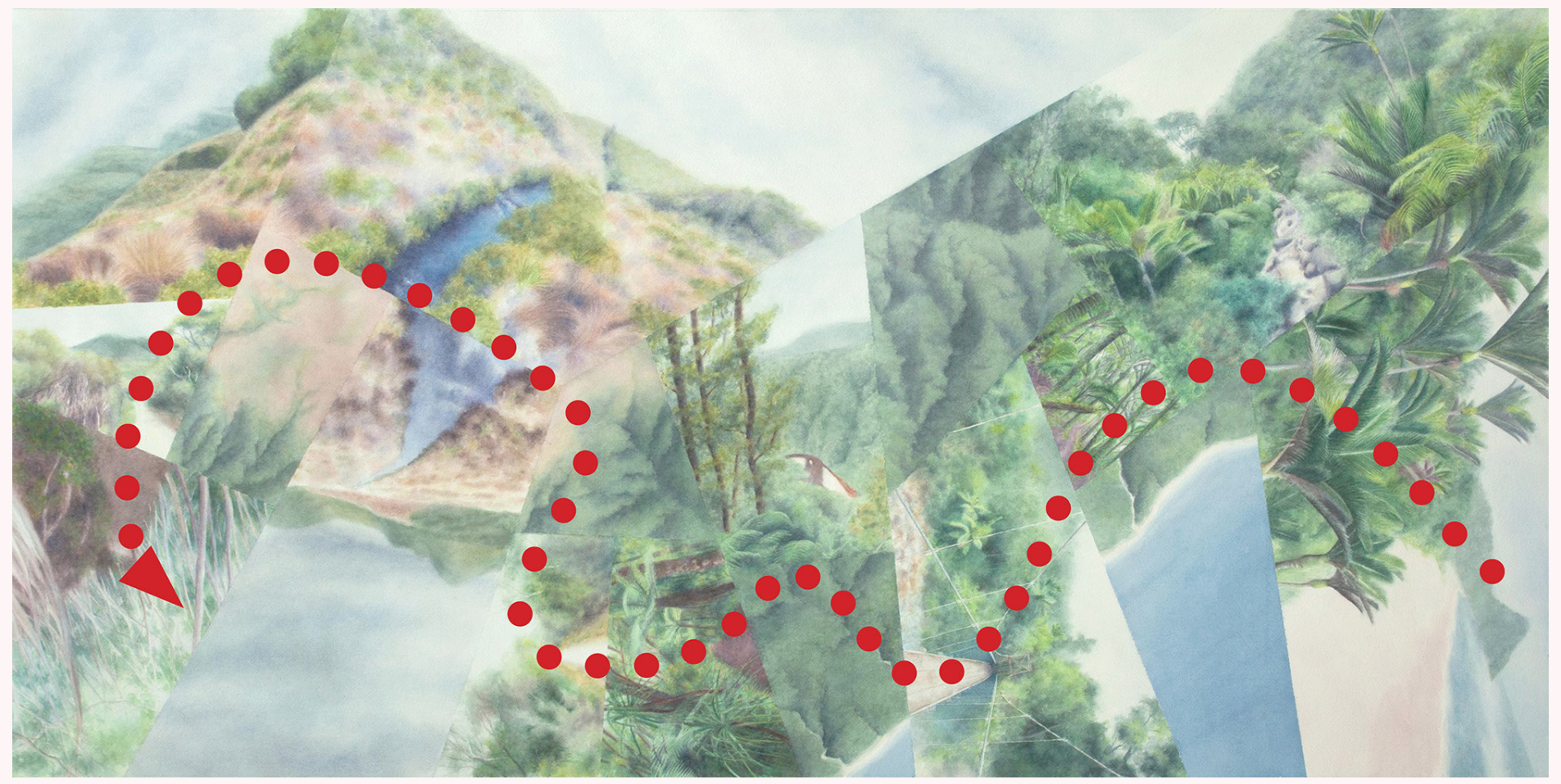

Great Walk (2019) overlaid with an abstracted hiking route, inspired by a trek along the Heaphy Track in Kahurangi National Park, New Zealand. Watercolor on paper with digital overlay, $24 " \times 48 "$.

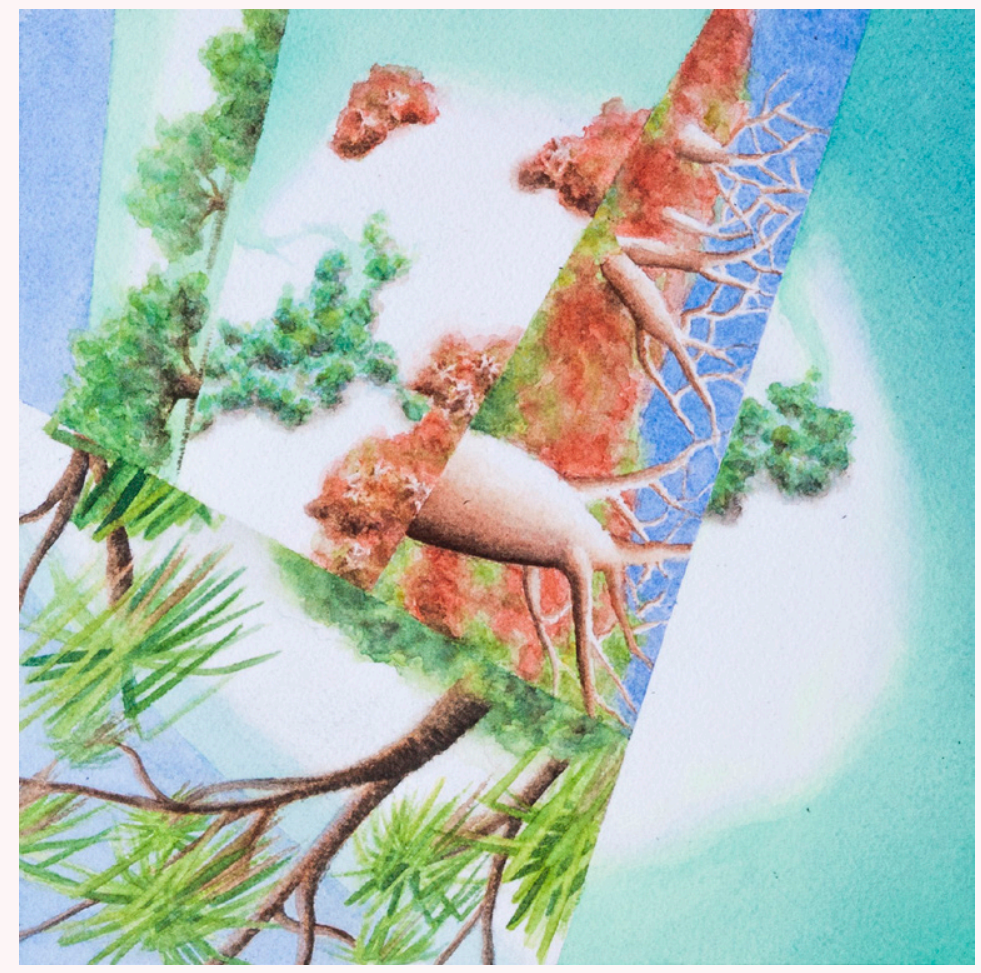

Pearl Isle (2018), an imaginary island combining elements of the Kimberley region of Australia. Watercolor on paper, 8" $\times 8 "$.

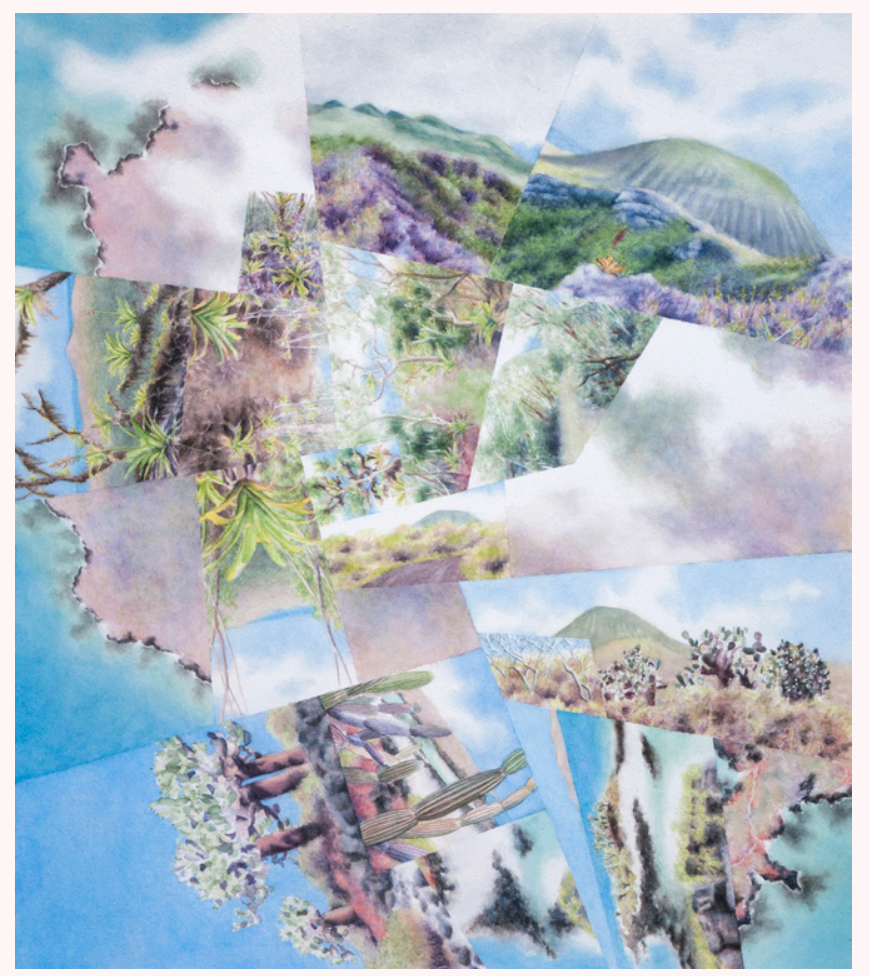

Floreana (2019), inspired by Floreana Island in the Galápagos. Watercolor on paper, 24"×21". 
range from accentuated versions of the real thing to completely imagined, invented by mixing and matching pieces of real locales. Lately I have taken a greater interest in the truer-to-experience variety, given the engaging challenge of mapping my recollections and idealizations onto something resembling the real geographical relationships, plus an aim to overlay the "compression" narrative with an expression of my distress at the growing ecological fragility of these places. It is not coincidental that the complex ecological zonation patterns and tiny natural relicts that I find so inspiring are particularly susceptible to climate change, invasive species, and other environmental threats. But I think of my urge to further compress them in $2 \mathrm{D}$, into something I can intellectually grasp and control, as a protective impulse rather than a desire to make them any more fragile than they are.

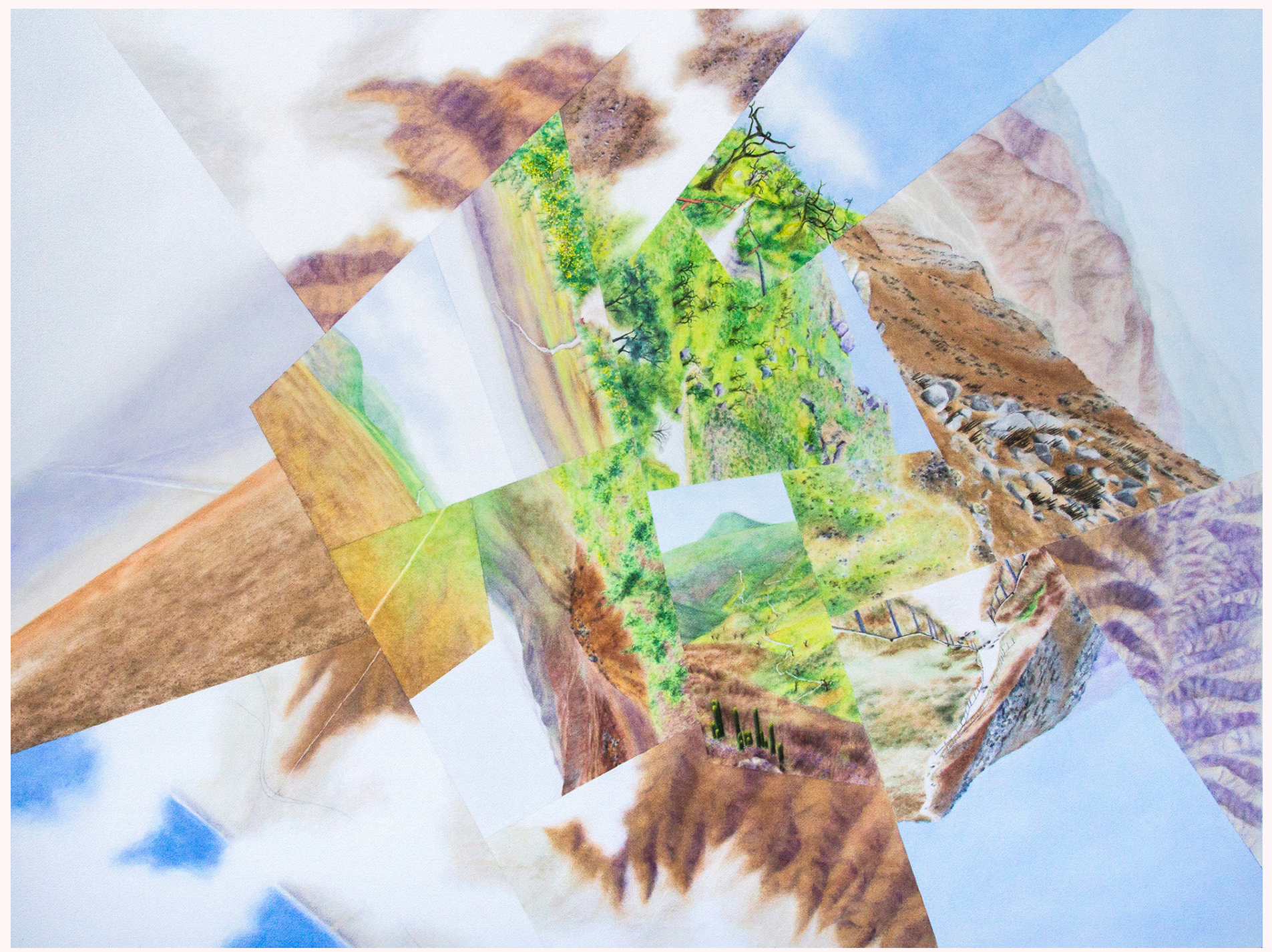

Fog Meadows (2020), inspired by the Lomas de Lachay, a fog-fed oasis in the coastal desert of Peru. Watercolor on paper, 36"x48". 